MATEC Web of Conferences 3, 01074 (2013)

DOI: $10.1051 /$ matecconf/20130301074

(C) Owned by the authors, published by EDP Sciences, 2013

\title{
Relationship of thermodynamic properties between solid and liquid states in $A^{\text {III }}-B^{\mathrm{V}}$ systems
}

\author{
N.I. Ilinykh ${ }^{1}$ and V.P. Vassiliev ${ }^{2}$ \\ ${ }^{1}$ Ural Technical Institute of Telecommunications and Informatics, 15, Repin Str., Yekaterinburg 620109, Russia \\ ${ }^{2}$ Chemistry Department, Moscow State University, Leninskiye Gory, Moscow 119992, Russia
}

\section{Introduction}

Nowadays the materials used in electronic engineering consist of several elements (more than 5 as a rule) and that is why it is correctly to speak not about the separate material phases, but about the formation of the complex structures. It is necessary to improve our knowledge about the structure of liquid alloys in order to obtain the solid alloys with fixed properties, because heat treatment of the melt can influence greatly on properties of solidified materials. Investigation of the behavior of these materials at different conditions, such as high or low temperatures, high pressure, aggressive media etc is important from practical point of view.

The binary and ternary $\mathrm{A}^{\mathrm{III}}-\mathrm{B}^{\mathrm{V}}$ semiconductor solid solutions and their compounds are widely used in different fields of industry. $\mathrm{A}^{\mathrm{III}} \mathrm{B}^{\mathrm{V}}$ compounds are the nearest electronic analogous of silicon and germanium compounds. They belong to diamond-like group of semiconductor materials. All of them, except for In, Ga and $\mathrm{Al}$ nitrides, have cubic crystalline structure of zinc blender - sphalerite, whereas wurtzite $\mathrm{HCP}$-structure is characteristic for nitrides.

The preliminary thermodynamic estimation is necessary to predict and check the semiconductor multifunctional structures of complex composition and to create the flexible technologies, that determine the general technical progress of electronic engineering. Therefore the aims of presented work are following:

i. Thermodynamic modeling of equilibrium composition of gas and condensed phases which appear when heating of $\mathrm{Al}, \mathrm{Sb}, \mathrm{In}, \mathrm{Ga}, \mathrm{GaSb}$, AlSb, InSb takes place.

ii. Investigation of equilibrium composition and thermodynamic characteristics of binary $\mathrm{Ga}-\mathrm{Sb}$, $\mathrm{Al}-\mathrm{Sb}$, In-Sb alloys in the wide range of temperatures in the atmosphere of argon and oxygen.

iii. Investigation of relationship between the thermochemical properties of semiconductor compounds, equilibrium composition and thermodynamic characteristics of $\mathrm{A}^{\mathrm{III}}-\mathrm{B}^{\mathrm{V}}$ melts in the wide range of temperatures and compositions.

\section{Method of investigation}

Investigation was carried out using the thermodynamic modeling method. As a software the program complex TERRA was used. This program was created in Bauman Moscow State Technical University.

The melt structure was described by the model of ideal solutions (IS) and by the model of ideal solutions of interaction products (ISIP) [1, 2]. Last model is a particular case of the model of ideal associated solutions [3]. It is constructed using following assumptions:

i. In the initial metallic system A-B with the strong interaction between the components, the composition of the melt consists of the atoms of pure components and all the associates $\left[\mathrm{A}_{\mathrm{x}} \mathrm{B}_{\mathrm{y}}\right]$ that are equal to real compounds, existing on the phase diagram of this system.

ii. Thermodynamic properties of the associates are considered to be the same as for compounds at melt temperature.

iii. Heats of mixing between $\mathrm{A}, \mathrm{B}$ and associates $\left[\mathrm{A}_{\mathrm{x}} \mathrm{B}_{\mathrm{y}}\right]$ are equal to 0 .

iv. Entropy of mixing is calculated as for ideal solutions.

For the realization of thermodynamic simulation the corresponding data base was formed, which contains information about the properties of the substances in different states of aggregation (standard enthalpies and entropies of formation, temperature dependences of heat capacities, so on). Information about these properties was undertaken from the literature [4-10].

\section{Thermodynamic modeling of $A^{\prime \prime \prime} B^{V}$ when heating in oxygen and argon}

In the presented work we took $\mathrm{Ga}, \mathrm{Al}$ and $\mathrm{In}$ antimonides as example.

The modeling was executed at the common pressure of $\mathrm{P}=10^{5} \mathrm{~Pa}$ and temperature interval $\mathrm{T}=300-3000 \mathrm{~K}$, initial content was $\operatorname{Ar}\left(\mathrm{O}_{2}\right): \mathrm{X}=1: 1(\mathrm{X}=\mathrm{InSb}, \mathrm{GaSb}$, 
$\mathrm{AlSb})$. The following elements and compositions (components of system) were taken into account: gaseous: $\mathrm{Ar}, \mathrm{Ga}, \mathrm{e}^{-}, \mathrm{Ga}^{+}, \mathrm{Sb}, \mathrm{Sb}_{2}, \mathrm{Sb}_{3}, \mathrm{Sb}_{4}, \mathrm{Sb}^{+}, \mathrm{In}, \mathrm{In}^{+}$, $\mathrm{Al}, \mathrm{Al}_{2}, \mathrm{Al}^{+}, \mathrm{O}, \mathrm{O}_{2}, \mathrm{SbO}, \mathrm{SbO}_{2}, \mathrm{Sb}_{4} \mathrm{O}_{6}, \mathrm{O}_{3}, \mathrm{O}^{+}, \mathrm{O}_{2}^{+}, \mathrm{O}^{-}$, $\mathrm{O}_{2}^{-}, \mathrm{SbO}_{2}^{-}, \mathrm{GaO}, \mathrm{Ga}_{2} \mathrm{O}, \mathrm{InO}, \mathrm{In}_{2} \mathrm{O}$; condenced: $\mathrm{Ga}, \mathrm{Sb}$, In, Al, GaSb, InSb, AlSb, $\mathrm{Sb}_{2} \mathrm{O}_{3}, \mathrm{Sb}_{2} \mathrm{O}_{4}, \mathrm{Sb}_{2} \mathrm{O}_{5}, \mathrm{Ga}_{2} \mathrm{O}_{3}$, $\mathrm{InO}, \mathrm{In}_{2} \mathrm{O}, \mathrm{Al}_{2} \mathrm{O}_{3}$.

The equilibrium composition of gaseous and condensed phases was determined. The basic peculiarities in the behavior of the components are revealed.

\subsection{Peculiarities in component behavior at heating in argon atmosphere:}

- The condensed phases, appearing at heating $\mathrm{Ga}, \mathrm{Al}$ and In antimonides up to the melting temperature, have $\mathrm{GaSb}, \mathrm{AlSb}$ and InSb structures respectively.

- At $\mathrm{T} \geq \mathrm{T}_{\mathrm{m}}$ some small amount of the metal ( $\left.\mathrm{Ga}, \mathrm{Al}, \mathrm{In}\right)$ appears, however it means that no dissociation of antimonides takes place and the melting is accompanied by evaporation only.

- The main components in gas phase are: Ar (which content remains the stable), $\mathrm{Sb}, \mathrm{Sb}_{2}, \mathrm{Al}, \mathrm{Ga}$ and $\mathrm{In}$.

- The content (partial pressure) of $\mathrm{Sb}, \mathrm{Al}, \mathrm{Ga}, \mathrm{In}$ increase in all the temperature range, whereas the partial pressure for $\mathrm{Sb}_{2}, \mathrm{Sb}_{3}, \mathrm{Sb}_{4}$ and $\mathrm{Al}_{2}$ grow up to $\mathrm{T}$ $\approx 2400 \mathrm{~K}$ and then go down due to dissociation.

\subsection{Peculiarities in component behavior at heating in oxygen atmosphere:}

- The main components of condensed phase appearing at the heating of $\mathrm{GaSb}, \mathrm{AlSb}$ and InSb alloys are $\mathrm{Sb}$, $\mathrm{Sb}_{2} \mathrm{O}_{2}$ and $\mathrm{Me}_{2} \mathrm{O}_{3}(\mathrm{Me}=\mathrm{Ga}, \mathrm{Al}, \mathrm{In})$.

- The pure $\mathrm{Sb}$ exists in the range $300-1800 \mathrm{~K}$, whereas $\mathrm{Sb}_{2} \mathrm{O}_{3}$ appears at higher temperatures (up to $1900 \mathrm{~K}$ in Ga-Sb, $2500 \mathrm{~K}$ in $\mathrm{Al}-\mathrm{Sb}$ and $\mathrm{In}-\mathrm{Sb}$ ). The content of $\mathrm{Me}_{2} \mathrm{O}_{3}$ goes down at $\mathrm{T} \geq 1900 \mathrm{~K}$.

- Oxygen, oxides and argon are the main components in gas phase. Their partial pressures increase with temperature, but at $\mathrm{T} \sim 2000 \mathrm{~K}$ the dissociation of oxides starts.

\section{Thermodynamic modeling of Ga-Sb, In-Sb, Al-Sb melts}

Experimental and theoretical investigations of thermodynamic properties of $\mathrm{Ga}-\mathrm{Sb}, \mathrm{Al}-\mathrm{Sb}$ and $\mathrm{In}-\mathrm{Sb}$ systems are presented good enough in solid state. However, for liquid phase the information is lack [1320].

In our work the modeling was executed in atmosphere of argon at the common pressure of $\mathrm{P}=10^{5} \mathrm{~Pa}$ and temperature and concentration intervals, corresponding to regions of liquid state on phase diagrams of binary Ga$\mathrm{Sb}, \mathrm{In}-\mathrm{Sb}, \mathrm{Al}-\mathrm{Sb}$ systems $[11,12]$ : Ga-Sb, In-Sb systems: $\mathrm{T}=1000-1600 \mathrm{~K}, 0 \leq \mathrm{x}_{\mathrm{Ga}(\mathrm{In})} \leq 1$, Al-Sb system: $\mathrm{T}=$ $1300-1700 \mathrm{~K}, 0 \leq \mathrm{x}_{\mathrm{Al}} \leq 1$, where $\mathrm{x}_{\mathrm{Ga}}, \mathrm{x}_{\mathrm{In}}$ and $\mathrm{x}_{\mathrm{Al}}$ is initial content of gallium, indium and aluminum in the melt (mole fraction), respectively.
Modeling system consists of the melt and the gas phase above melt. The content of components in the melt is determined by equilibria state of the all system.

According to the phase diagrams, only one compound with equiatomic composition exists in all above-indicated binary systems. These compounds have stable crystalline structure up to the melting point.

The melt structure was described by the model of ideal solutions (IS) and by the model of ideal solutions of interaction products (ISIP). In the model of ideal solutions $\mathrm{Ga}, \mathrm{Sb}, \mathrm{Al}$ and $\mathrm{In}$ atoms were taken into account as the component of melts only. In ISIP model the melts consist of $\mathrm{Ga}, \mathrm{Sb}, \mathrm{Al}$ and $\mathrm{In}$ atoms and associates corresponding to the $\mathrm{GaSb}, \mathrm{InSb}, \mathrm{AlSb}$ compositions.
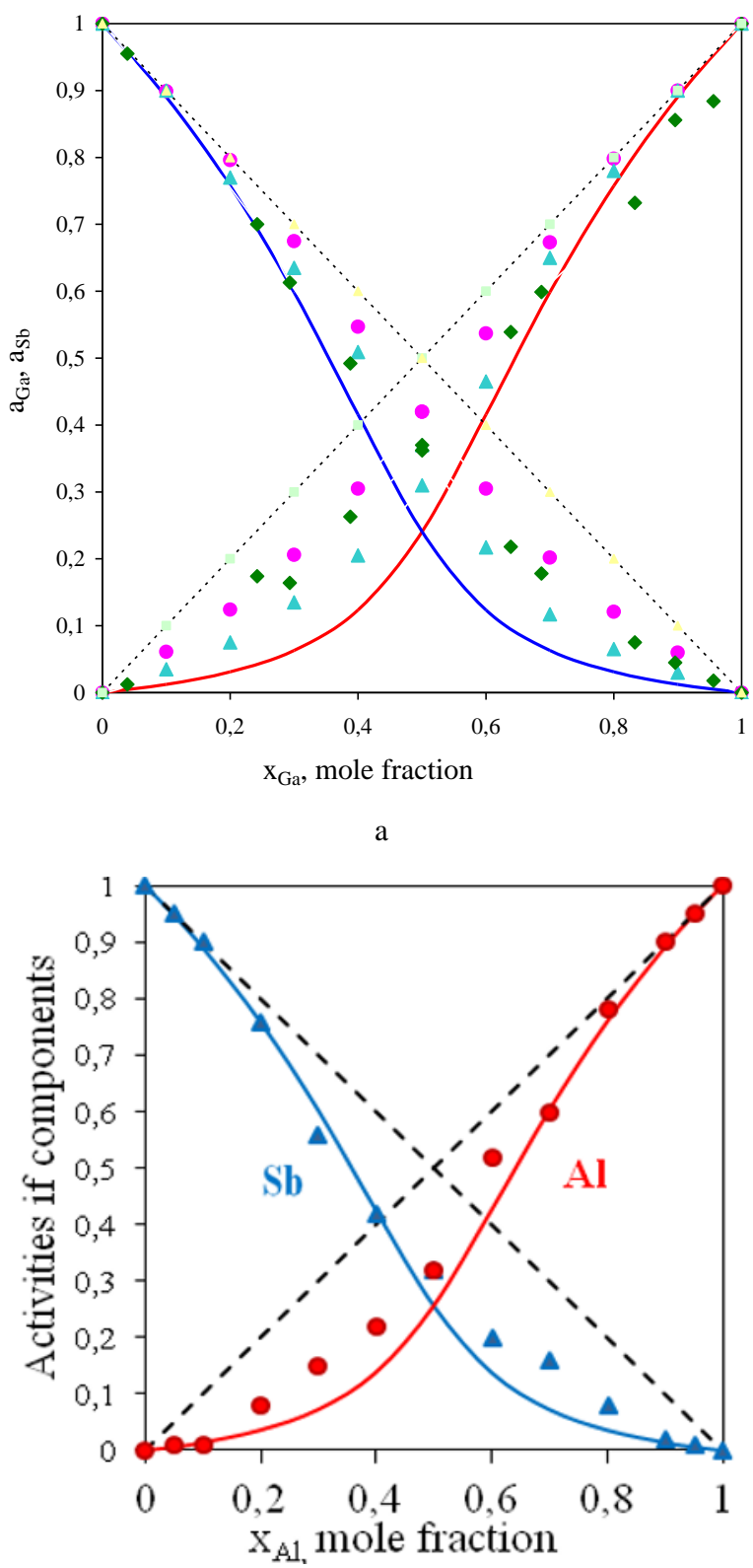

b

Fig.1. Activities of components of Ga-Sb and Al-Sb melts. $\mathrm{a}-\mathrm{Ga}-\mathrm{Sb}$ system, $\mathrm{T}=1000 \mathrm{~K}$ : solid lines - our data, $\Delta$ - taken from [13], $\mathbf{-}$ - taken from [14], - taken from [15] b - Al-Sb system, T = $1300 \mathrm{~K}$ : solid lines - our data; $\boldsymbol{\Delta}, \bullet-$ taken from [16]. 
The activities of components, integral and partial excess Gibbs energies, integral excess enthalpies, entropies and equilibrium composition of melts were obtained.

It was shown, that activities of the components have big negative deviations from Raoult's law (see Fig. 1, for example).

Composition of $\mathrm{Ga}-\mathrm{Sb}$ and $\mathrm{AlSb}$ melts at different temperatures is presented in the Fig. 2.
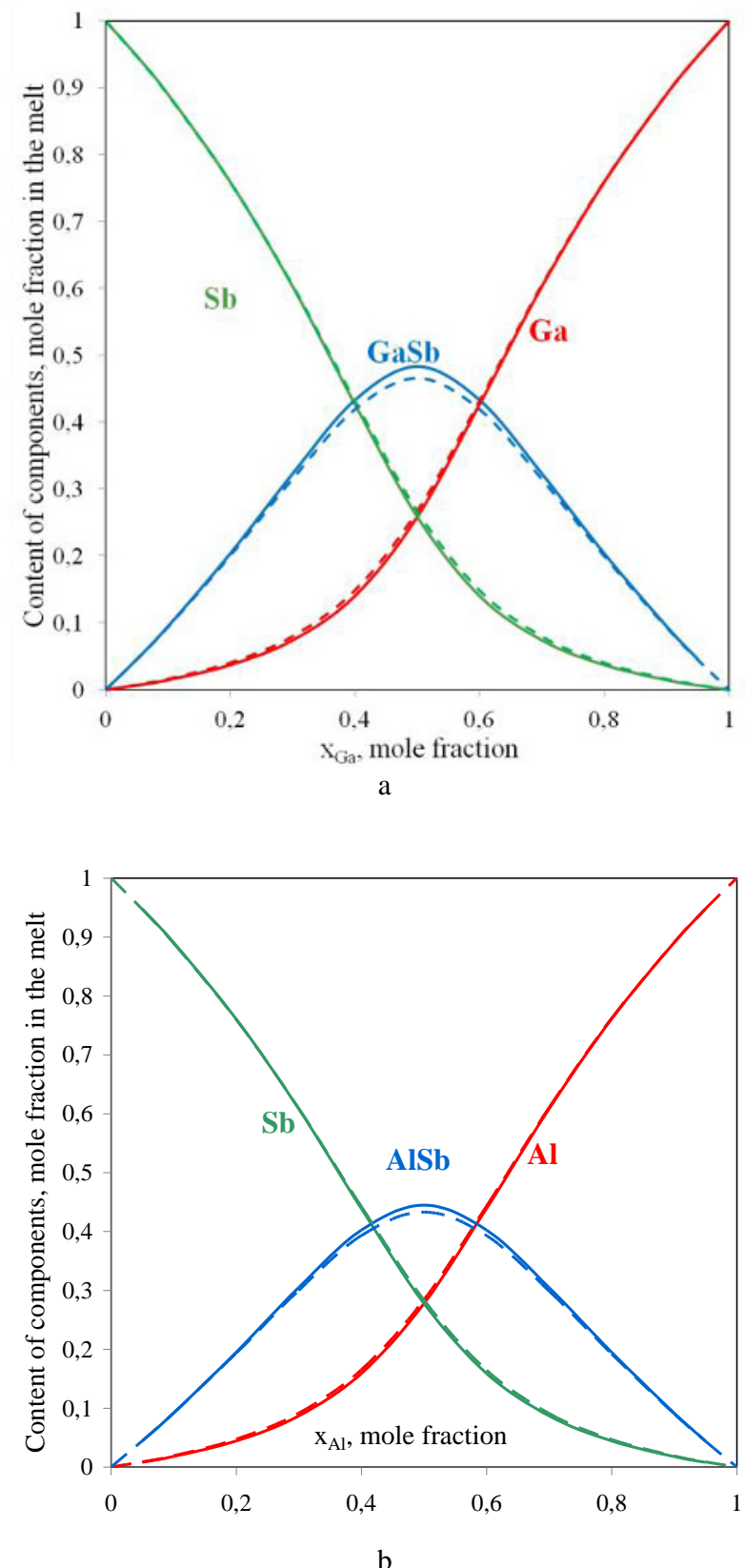

Fig.2. Composition of Ga-Sb (a) and AlSb (b) melts. Solid lines $-\mathrm{T}=1000 \mathrm{~K}$ (a) and $\mathrm{T}=1373 \mathrm{~K}(\mathrm{~b})$. Dotted lines $-\mathrm{T}=1473 \mathrm{~K}(\mathrm{a})$ and $\mathrm{T}=1353 \mathrm{~K}(\mathrm{~b})$.

Analogous dependences are constructed for all investigated systems. One can see, that maximum content of components of melts are at the correlation of elements typical to formation of really existing compounds according to phase diagrams.
Concentration dependencies of integral excess Gibbs energies, entropies and enthalpies are no monotonous. These facts justify, that strong interaction between atoms of different sorts takes place.

The rigid relation between the enthalpies of formation, melting temperatures and the sum of the atomic numbers of the elements for isostructural $\mathrm{A}^{\mathrm{III}} \mathrm{B}^{\mathrm{V}}$ phases of sphalerite and wurtzite types were determined in [7-9]. In the present work the relation between the thermodynamic functions of antimonides of indium, gallium and aluminum taken from [6-10] and maximum values of the excess integral characteristics of mixing of the melts $v s$ the number $\left(\mathrm{N}_{\mathrm{A}}\right)$ of the Periodic system of the elements was conformed. It was found, that good enough correlation between the properties of compounds and characteristics of melts takes place.

\section{Conclusions}

Investigation of the equilibrium composition of condensed media and gaseous phase forming at the heating of $\mathrm{GaSb}, \mathrm{InSb}, \mathrm{AlSb}$, is carried out. It was established, that content of components depends on the temperature and initial gas atmosphere. The regions of existing of different phases were determined.

Temperature and concentration dependencies of the equilibrium composition and activities of components, integral excess Gibbs energies? Enthalpies of $\mathrm{Ga}-\mathrm{Sb}$, In$\mathrm{Sb}, \mathrm{Al}-\mathrm{Sb}$ melts were obtained.

It was established, that the activities of the components have big negative deviations from Raol's low. These facts justify, that strong interaction between atoms of different sorts takes place.

Some regularities of behaviour of thermochemical properties of compounds and characteristics of $\mathrm{A}^{\mathrm{III}}-\mathrm{B}^{\mathrm{V}}$ binary melts depend on the number $\left(\mathrm{N}_{\mathrm{A}}\right)$ of the element in the Periodic system were conformed.

The results of thermodynamic modeling allow us to predict the conditions of production of materials with optimal composition.

\section{References}

1. G.B. Sinarev, N.A. Vatolin, B.G. Trusov, G.K. Moiseev, The using of IBM for the thermodynamic calculations of metallurgical processes, Nauka, Moscow (1983)

2. N.A. Vatolin, G.K. Moiseev, B.G. Trusov, Thermodynamic modeling in high-temperature inorganic systems, Metallurgia, Moscow (1994)

3. I. Prigogin, R. Defay, Chemical thermodynamics, Nauka, Novosibirsk (1966)

4. H. Yokokawa, J. Nat. Chem. Laboratory for Industry Japan 8327 (1988)

5. I. Barin, O. Knacke, O. Kubashewski, Thermochemical properties of inorganic substances. Supplement, Springer-Verlag, Berlin-HeidelbergNew-York (1977)

6. V.P. Vassiliev, Inorg. Mater. 40524 (2004)

7. V.P. Vassiliev, J.-C. Gachon, Inorg. Mater. 421293 (2006) 
8. V.P. Vassiliev, B. Legendre, V.P. Zlomanov, Intermetallics 191891 (2011)

9. V.P. Vassiliev, W. Gong, A.F. Taldrik, A.F. Kulinich, J. Alloys and compounds 552248 (2013)

10. C. Chatillon, I. Ansara, A. Watson, B.B. Argent, CALPHAD, 14203 (1990)

11. I. Ansara et al., CALPHAD 18177 (1994)

12. Phase diagrams of binary metallic systems: Handbook, N.P. Ljakishev Ed., Mashinostroenie, Moskow (1997)

13. C. Bergman, Y.M. Miggianu, M. Laffite, High Temperature-High Pressure, 653 (1974)

14. T.J. Andersson, T.L. Aselage, L.F. Donaghey, J. Chem. Thermodynamics 15927 (1983)

15. M. Gambino and J.-P. Bros, J. Chem. Thermodynamics 7443 (1975)

16. G.I. Batalin, G.I. Beloborodowa, V.P. Kasimirov, Thermodynamics and structure of liquid alloys based on aluminium, Metallurgia, Moscow (1984)

17. K. Yamaguchi et al., Materials Transactions JIM, 35(3) 432 (1995)

18. V.M. Glazov, L.M. Pavlova, A.L. Lomov, E.B. Il'ina, Zh. Fiz. Khim. 661213 (1992)

19 C. Girard et al., J. of Less-Common metals, 128101 (1987)

20. B. Predel, U. Shallner, Mat. Sci. and Eng. 5(4) 210 (1970)

21. J. Šestak, V. Šestakova, Z. Zivkovic, D. Zivkovic, Pure \& Appl. Chem. 67(11) 1885 (1995)

22. S.K. Charkabarti, I.S. Jha, B.K. Jha, B.P. Singh, Scientific World 9(9) 13 (2011) 